\title{
The Role of Interferon in Hepatitis B Therapy
}

\author{
Vincent Rijckborst • Harry L. A. Janssen
}

Published online: 26 August 2010

(C) The Author(s) 2010. This article is published with open access at Springerlink.com

\begin{abstract}
Despite the introduction of new nucleos(t)ide analogues in recent years, peginterferon is still recommended as a potential first-line treatment option by current practice guidelines for the management of chronic hepatitis B. Peginterferon offers the advantage of higher sustained off-treatment response rates compared to nucleos(t)ide analogues because of its immunomodulatory effects. Sustained transition to the inactive hepatitis B surface antigen (HBsAg) carrier state can be achieved in about $30 \%$ of hepatitis B e antigen ( $\mathrm{HBeAg}$ )-positive patients and $20 \%$ of HBeAg-negative patients. Recent studies have focused on identification of pretreatment and on-treatment factors that allow the selection of patients who are likely to achieve a sustained response to peginterferon therapy in order to avoid the side-effects and costs associated with unnecessary treatment. Future studies need to address whether specific virologic benchmarks can guide individualized decisions concerning therapy continuation and whether peginterferon combined with new potent nucleos(t)ide analogues improves treatment outcomes.
\end{abstract}

\footnotetext{
V. Rijckborst

Department of Gastroenterology and Hepatology,

Erasmus MC University Medical Center Rotterdam,

's Gravendijkwal 230, Room Ca 415,

3015 CE Rotterdam, The Netherlands

e-mail: v.rijckborst@erasmusmc.nl

H. L. A. Janssen $(\bowtie)$

Department of Gastroenterology and Hepatology,

Erasmus MC University Medical Center Rotterdam,

's Gravendijkwal 230, Room Ha 204,

3015 CE Rotterdam, The Netherlands

e-mail: h.janssen@erasmusmc.nl
}

Keywords HBV· Antiviral therapy · Interferon Nucleos $(\mathrm{t})$ ide analogues

\section{Introduction}

Chronic hepatitis $\mathrm{B}(\mathrm{CHB})$ is one of the most serious and prevalent infectious diseases worldwide. It is estimated that about one third of the world's population has evidence of infection, current or remote, with the hepatitis B virus (HBV). Although safe and effective vaccines have been available for more than two decades, more than 350 million people worldwide are chronically infected with HBV [1]. Progression of HBV-related liver disease to cirrhosis, hepatic decompensation, and hepatocellular carcinoma (HCC) is estimated to result in 0.5 to 1.2 million deaths annually [1]. The dual immunomodulatory and antiviral agent interferon (IFN)- $\alpha$ has been a mainstay in the treatment of CHB since it was licensed for this indication in the early 1990s. Since 1998, considerable progress has been made in the treatment of $\mathrm{CHB}$ with the introduction of nucleos(t)ide analogues (NA), which directly inhibit HBV polymerase and provide, at least in the short term, a well-tolerated and effective alternative to IFN therapy [2]. IFN-based therapy also improved significantly by pegylation of IFN, which allowed a more convenient once-weekly dosing interval, with treatment efficacy equal or superior to conventional IFN [3]. Currently, IFN (conventional or pegylated [PEG]) and five NA (lamivudine, telbivudine, adefovir, entecavir, and tenofovir) have been approved for the treatment of CHB in many parts of the world. Along with the introduction of these agents, the complexity of antiviral therapy for CHB has increased, leading to the development of multiple 
international practice guidelines in recent years $[4,5]$. All guidelines recommend both PEG-IFN and NA as initial treatment options, but the optimal choice for individual patients remains controversial. In this article, we review the role of IFN in CHB therapy.

\section{Indications for Treatment}

\section{Phases of Chronic Hepatitis B}

Patients with CHB may present in one of four phases $[4,5]$. During the immunotolerant phase, hepatitis $\mathrm{B}$ e antigen (HBeAg) is detectable and serum HBV DNA is high, but serum alanine aminotransferase (ALT) levels are normal and liver histology shows minimal inflammation. This phase may last between 1 and 4 decades, but it can be much shorter or absent if the infection is acquired later in life. During the immunoactive phase, $\mathrm{HBeAg}$ remains detectable, but the host immune response against the virus results in a decline in serum HBV DNA and hepatic inflammation. Activation of the host immune response can result in $\mathrm{HBeAg}$ loss and seroconversion to anti-HBe. HBeAg seroconversion is usually followed by the immune-control phase (inactive hepatitis B surface antigen [HBsAg] carrier state), characterized by a low serum HBV DNA level and minimal hepatic inflammation. However, in a significant proportion of HBeAg-negative patients, viral replication recurs or persists at high levels, resulting in HBeAg-negative active CHB. This phase of the infection develops spontaneously through mutations in the precore or basal core promoter region that reduce the expression of $\mathrm{HBeAg}[6]$.

\section{Practice Guidelines}

In general, treatment is recommended for patients with high serum HBV DNA and elevated ALT levels, indicating the active host immune response against HBV. The 2009 American Association for the Study of Liver Diseases (AASLD) guidelines advocate antiviral treatment for patients who remain $\mathrm{HBeAg}$ positive with serum HBV DNA levels greater than $20,000 \mathrm{IU} / \mathrm{mL}$ combined with persistently elevated ALT levels (greater than 2 times the upper limit of normal [ULN] over a 3-6 month period) [5]. The same HBV DNA and ALT criteria apply to HBeAg-negative patients, but these patients should also be considered for treatment if the HBV DNA concentration is greater than $2,000 \mathrm{IU} / \mathrm{mL}$ combined with a liver biopsy showing moderate to severe necroinflammation and/or fibrosis [5]. Indications for treatment are the same for $\mathrm{HBeAg}$-positive and $\mathrm{HBeAg}$-negative patients according to the current HBV guidelines of the European Association for the Study of the Liver (EASL) [4]. Antiviral therapy should be considered if HBV DNA levels exceed 2,000 IU/mL, ALT levels are greater than 1 time ULN, and if a liver biopsy shows moderate to severe necroinflammation and/or fibrosis [4].

\section{Goals of Antiviral Therapy}

The ideal outcome of treatment for any chronic infection is eradication of the infectious agent. Unfortunately, complete eradication of HBV is scarcely achieved with the currently available treatment options for $\mathrm{CHB}$, because covalently closed circular DNA (cccDNA) persists in host hepatocytes [7]. Therefore, antiviral therapy aims at the prevention of cirrhosis, hepatic decompensation, and HCC [8]. Because these adverse clinical events develop only after decades of infection, clinical studies have focused on varying shortterm, surrogate outcomes to assess treatment efficacy $[5,8]$. $\mathrm{HBeAg}$ seroconversion is frequently used as a primary endpoint in HBeAg-positive patients treated with PEG-IFN. Most patients enter an inactive carrier state after achieving $\mathrm{HBe} A g$ seroconversion, characterized by low or undetectable HBV DNA levels and normalization of ALT levels. Long-term follow-up studies have demonstrated that HBeAg seroconversion is associated with increased survival and a reduced risk of developing HCC [9-11]. HBeAg seroconversion is by definition not possible in $\mathrm{HBeAg}$-negative patients. Thus, suppression of HBV DNA to low or undetectable levels in combination with normalization of ALT is considered the most important treatment goal. The level of HBV DNA applied to define response to therapy differs between PEG-IFN and NA therapy because their modes of action differ. The main goal of PEG-IFN therapy is to achieve sustained immunologic control over the virus, whereas therapy-maintained suppression of HBV DNA to undetectable levels is required during NA therapy to prevent the emergence of antiviral resistance [2]. Response to PEG-IFN therapy is defined by the sustained presence of an HBV DNA level below 2,000 IU/mL according to the European guidelines [4]. Large population studies have demonstrated that HBsAg-positive patients with an HBV DNA concentration below this level of viral replication have a reduced risk of progression to cirrhosis and HCC [9, 12, 13]. Finally, serum HBsAg loss comes as close to clinical cure as one can expect to achieve in CHB and is clearly associated with improved outcomes, provided that $\mathrm{HBsAg}$ clearance occurs before the development of cirrhosis [14].

\section{Interferon- $\alpha$}

IFNs were first recognized in 1957 for their ability to interfere with viral activity. IFNs are naturally occurring cytokines with immunomodulatory, antiproliferative, and 
antiviral properties. Multiple naturally occurring forms of IFN exist, including IFN- $\alpha$ produced by lymphocytes [15]. The effects of IFN- $\alpha$ are predominantly immunomodulatory, although this cytokine also exerts a limited direct antiviral effect on HBV. IFN- $\alpha$ binds to its cellular receptor and activates secondary messengers, resulting in the production of multiple proteins that are important for the defense of the cell against viruses. Immunomodulatory effects of IFN- $\alpha$ include enhancement of antigen presentation to the immune system, activation of natural killer (NK) cells and other immune cells, and increased production of cytokines. Antiviral effects include degradation of viral mRNA, inhibition of viral protein synthesis, and prevention of infection of cells.

Modification of IFN through the attachment of a polyethylene glycol (PEG) molecule led to improved pharmacokinetic and pharmacodynamic properties and has largely replaced conventional IFN. PEG-IFN is administered once weekly, resulting in a relatively continuous drug exposure during the dosing interval. Two types of PEG-IFN have been developed: a small linear 12$\mathrm{kDa}$ PEG, linked to IFN $\alpha-2 \mathrm{~b}$ (PEG-IFN $\alpha$-2b), and a large branched $40-\mathrm{kDa}$ PEG, linked to IFN $\alpha$-2a (PEG-IFN $\alpha-2 \mathrm{a}$ ) [16]. These molecules have different characteristics due to their difference in size and structure. PEG-IFN $\alpha$-2a has a longer half-life (about $80 \mathrm{~h}$ ), is mainly catabolized in the liver, and has active metabolites. PEG-IFN $\alpha-2 b$ is smaller and has a shorter half-life (about $40 \mathrm{~h}$ ) and may act as a pro-drug depot, slowly releasing IFN [16]. Both types of PEG-IFN were initially investigated for the treatment of chronic hepatitis C. Response rates were superior compared to conventional IFN with a comparable tolerability profile [16]. PEG-IFN $\alpha$-2a is registered for the treatment of both $\mathrm{HBeAg}$-positive and $\mathrm{HBeAg}$-negative CHB as a 48-week course, in a dosage of $180 \mu \mathrm{g}$ administered subcutaneously once a week. PEG-IFN $\alpha-2 b$ has only been registered for the treatment of $\mathrm{CHB}$ in countries with a high prevalence of $\mathrm{HBV}$ infection.

\section{Interferon-Based Therapy for HBeAg-Positive Chronic Hepatitis B}

\section{Response Rates}

A meta-analysis showed that a higher percentage of IFNtreated $\mathrm{HBeAg}$-positive patients developed a virologic response compared to untreated patients [17]. Sustained clearance of $\mathrm{HBeAg}$ and HBV DNA was achieved in about one third of patients by 3 to 6 months after discontinuation of treatment. Furthermore, HBsAg loss was observed more often in patients treated with IFN [17]. Pegylation of IFN allowed a more convenient once-weekly dosing interval. PEG-IFN $(180 \mu \mathrm{g}$, once weekly) resulted in a larger decline in $\mathrm{HBV}$ DNA levels and a higher rate of $\mathrm{HBeAg}$ seroconversion after 24 weeks of follow-up (33\% vs $25 \%$ ) compared to standard IFN $\alpha$-2a (4.5 million units, three times weekly) [3].

The use of PEG-IFN $\alpha$-2a and PEG-IFN $\alpha$-2b for HBeAgpositive CHB was evaluated in two pivotal trials (Table 1) [18, 19]. PEG-IFN monotherapy administered for 1 year resulted in $\mathrm{HBeAg}$ seroconversion in about one third of HBeAg-positive patients after 24 to 26 weeks of treatmentfree follow-up. Sustained viral suppression (serum HBV DNA $<100,000$ to 200,000 copies $/ \mathrm{mL}$ ) occurred in $27 \%$ to $32 \%$ of patients. Serum HBV DNA was suppressed below 400 copies $/ \mathrm{mL}$ in $7 \%$ to $14 \%$ of patients after 6 months of follow-up. In both studies, PEG-IFN monotherapy was compared to PEG-IFN and lamivudine (LAM) combination therapy. Although the latter was associated with more potent viral suppression during the treatment phase, combination therapy did not lead to higher sustained response rates $[18$, 19]. At 6 months after discontinuation of PEG-IFN therapy, HBsAg seroconversion was observed in $3 \%$ to $5 \%$ of HBeAg-positive patients (Table 1).

We recently reported long-term follow-up (mean duration 3 years) results in 172 patients treated with PEG-IFN $\alpha-2 b$ with or without LAM [20••]. Among initial responders (defined as $\mathrm{HBeAg}$ negativity at 26 weeks posttreatment), HBeAg clearance was sustained in $81 \%$ of cases and HBsAg loss increased to $30 \%$. Overall, HBsAg became negative in $11 \%$ of patients at the last visit $[20 \bullet \cdot$.

\section{Predictors of Response at Baseline}

Because treatment with PEG-IFN is expensive and is associated with considerable side-effects, identification of baseline parameters associated with the chance of achieving sustained response has gained attention recently, particularly

Table 1 Rates of sustained virologic and biochemical response to PEG-IFN in HBeAg-positive chronic hepatitis $\mathrm{B}^{\mathrm{a}}$

\begin{tabular}{lll}
\hline $\begin{array}{l}\text { Response after } \\
\text { 24-26 weeks of } \\
\text { follow-up }\end{array}$ & $\begin{array}{l}\text { PEG-IFN } \alpha \text {-2a } \\
\text { duration of treatment } \\
48 w k(N=271)\end{array}$ & $\begin{array}{l}\text { PEG-IFN } \alpha-2 \mathrm{~b} \\
\text { duration of treatment, } \\
52 w k(N=136)\end{array}$ \\
\hline HBV DNA $<10^{5}$ copies $/ \mathrm{mL}$ & $32 \%$ & $27 \%$ \\
HBV DNA $<400$ copies $/ \mathrm{mL}$ & $14 \%$ & $7 \%$ \\
HBeAg clearance & $34 \%$ & $36 \%$ \\
HBeAg seroconversion & $32 \%$ & $29 \%$ \\
HBsAg clearance & $3 \%$ & $7 \%$ \\
HBsAg seroconversion & $3 \%$ & $5 \%$ \\
ALT normalization & $41 \%$ & $32 \%$ \\
\hline
\end{tabular}

${ }^{\text {a }}$ Different assays were used for quantification of HBV DNA in these studies $A L T$ alanine aminotransferase; $H B e A g$ hepatitis $\mathrm{B}$ e antigen; $H B s A g$ hepatitis B surface antigen; $H B V$ hepatitis B virus; PEG-IFN pegylated interferon

(Data from Janssen et al. [18] and Lau et al. [19]) 
Fig. 1 Average predicted chances of sustained response for $\mathrm{HBV}$ genotypes $\mathrm{A}$ to $\mathrm{D}$ based on the presence of low $(<2 \times \mathrm{ULN})$ or high $(\geq 2 \times$ ULN) ALT levels, and low $\left(<9 \log _{10}\right.$ copies $\left./ \mathrm{mL}\right)$ or high $\left(\geq 9 \log _{10}\right.$ copies/mL) HBV-DNA levels. Low $<20 \%$; moderate $=$ $20 \%$ to $30 \%$; high $\geq 30 \%$ chance of sustained response.

ALT - alanine aminotransferase;

HBV - hepatitis B virus;

ULN — upper limit of normal

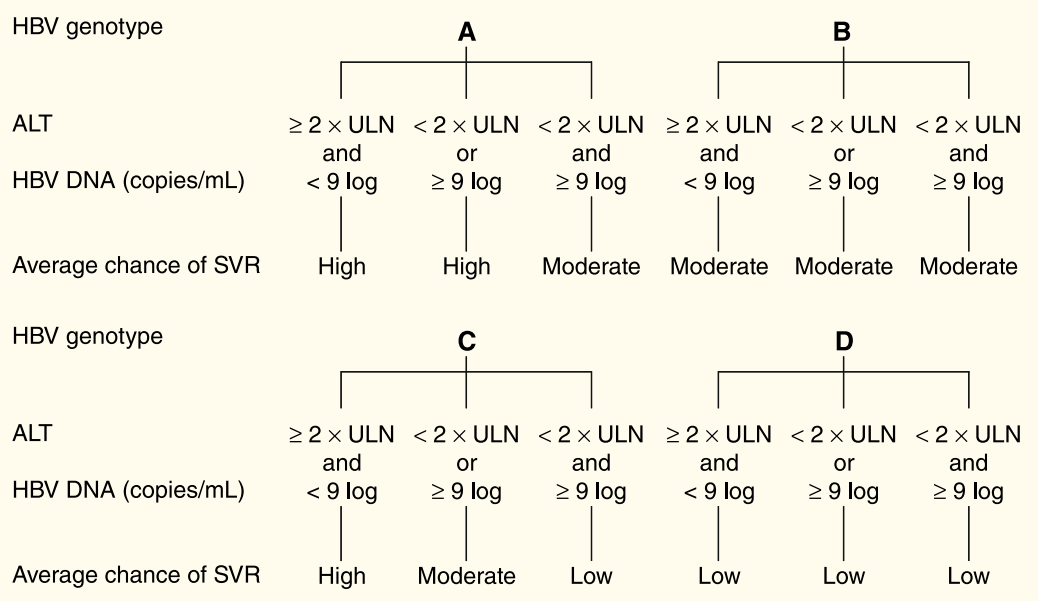

concerning HBV genotype. HBV is currently classified into eight genotypes (A to $\mathrm{H}$ ). HBV genotypes $\mathrm{A}$ and $\mathrm{D}$ are most common in Europe and North America, while genotypes B and $\mathrm{C}$ are predominant in Asia [21]. Genotype A was found to be associated with higher rates of sustained response to conventional IFN compared with genotype D [22]. Furthermore, a higher rate of IFN-induced HBeAg clearance was observed among genotype B infected patients compared with genotype C [23].

The importance of genotypes concerning responsiveness to IFN-based therapy was further emphasized in our study that pooled data from two pivotal trials investigating the efficacy of PEG-IFN in HBeAg-positive CHB [24••]. HBV genotype A, high baseline ALT, low baseline HBV DNA, female sex, and older age were predictive of a sustained response (defined as HBeAg loss and HBV DNA $<2,000 \mathrm{IU} / \mathrm{mL}$ 6 months after treatment) using univariate analysis. Next, we constructed a multivariable model allowing prediction of sustained response to PEG-IFN for individual patients with the use of readily available baseline parameters. (An automated calculator is available at www.liver-gi.nl/pegifn). Figure 1 shows average chances of sustained response based on the presence of low $(<2 \times \mathrm{ULN})$ or high $(\geq 2 \times \mathrm{ULN})$ ALT levels, and low $\left(<9 \log _{10}\right.$ copies $\left./ \mathrm{mL}\left[<2 \times 10^{8} \mathrm{IU} / \mathrm{mL}\right]\right)$ or high $\left(\geq 9 \log _{10}\right.$ copies $\left./ \mathrm{mL}\left[\geq 2.0 \times 10^{8} \mathrm{IU} / \mathrm{mL}\right]\right)$ HBV DNA levels for each genotype. General recommendations on whether to consider PEG-IFN therapy for individual patients based on a predicted probability of response above $30 \%$ are shown in Table 2.

The durability of response to PEG-IFN therapy may also be influenced by HBV genotype. Genotype A infected patients, who lost $\mathrm{HBeAg}$ at 26 weeks after treatment with PEG-IFN $\alpha-2 b$, more often remained negative for HBeAg compared to those infected with other genotypes at the end of 3 years of follow-up ( $96 \%$ vs $76 \%, P=0.06$ ). Furthermore, the rate of HBsAg loss was markedly higher in genotype A infected patients losing $\mathrm{HBeAg}$ at 26 weeks after treatment compared to patients infected with genotypes $\mathrm{B}, \mathrm{C}$, and $\mathrm{D}(58 \%$ vs $6 \%, P<0.001)[20 \bullet \cdot$.

\section{On-Treatment Predictors of Response}

Despite the availability of baseline predictors of response, considerable uncertainty remains as to whether an individual patient will benefit from PEG-IFN therapy. In the management of chronic hepatitis $\mathrm{C}$ virus (HCV) infection, stopping rules are used according to the magnitude and rapidity of HCV RNA decline. On-treatment monitoring of virologic factors may further improve prediction of response in the treatment of CHB as well. Frequent monitoring of HBV DNA levels during treatment has been established as a tool in the management of CHB [4, 5]. However, the benefit of monitoring the viral load during treatment with PEG-IFN is probably limited. Different patterns of viral decline during PEG-IFN $\alpha-2 b$ treatment for HBeAg-positive CHB have been described. Prediction of response based on viral decline during the first months of therapy was difficult, because a considerable response was observed, even in patients with a late or posttreatment decline of HBV DNA [25]. However, a recent study showed that addition of on-treatment HBV

Table 2 General recommendations for the use of PEG-IFN as firstline therapy for $\mathrm{HBeAg}$-positive chronic hepatitis B

\begin{tabular}{ll}
\hline HBV genotype & General recommendation \\
\hline A & Either high $\left(\geq 2 \times\right.$ ULN) ALT or low $\left(<9 \log _{10} \mathrm{cp} / \mathrm{mL}\right)$ \\
& HBV DNA levels \\
B and C & Both high $\left(\geq 2 \times\right.$ ULN) ALT and low $\left(<9 \log _{10} \mathrm{cp} / \mathrm{mL}\right)$ \\
& HBV DNA levels \\
D & PEG-IFN therapy is not recommended \\
\hline
\end{tabular}

$A L T$ alanine aminotransferase; $H B e A g$ hepatitis B e antigen; $H B V$ hepatitis B virus; PEG-IFN pegylated interferon; $U L N$ upper limit of normal

(Data from Buster et al. [24••]) 
DNA decline to the previously described prediction model improves prediction of sustained response, and it was recommended to discontinue therapy in patients in whom an HBV DNA decline of $2 \log _{10}$ at week 24 is not achieved [26].

In parallel with HBV DNA, quantitative assays for HBeAg and HBsAg have become available [27]. Fried et al. [28•] showed that monitoring serum HBeAg levels during PEG-IFN $\alpha$-2a treatment may help to predict the probability of subsequent $\mathrm{HBeAg}$ loss or seroconversion. At 24 weeks of PEG-IFN $\alpha$-2a therapy, high HBeAg levels had a greater negative predictive value (96\%) compared with HBV DNA levels at the same time point (86\%) [28•]. Serum HBsAg levels probably reflect intrahepatic cccDNA, the key replicative intermediate [29]. On-treatment reduction of HBsAg may reflect the immunomodulatory effects of IFN-based therapy resulting in reduced intrahepatic cccDNA concentrations [29, 30]. Indeed, responders to PEG-IFN therapy experience a steeper decline in HBsAg levels compared to nonresponders. Preliminary results from the PEG-IFN $\alpha-2 \mathrm{a}$ trial have indicated that the level of HBsAg at week 12 was associated with HBeAg seroconversion at 6 months posttreatment. Patients with $\mathrm{HBsAg}$ levels below $1,500 \mathrm{IU} / \mathrm{mL}$ at week 12 had $51 \%$ chance of response, in contrast to only $16 \%$ of patients with $\mathrm{HBsAg}$ levels greater than $20,000 \mathrm{IU} / \mathrm{mL}$ [31]. However, it is difficult to establish a clinically useful stopping-rule based on this study, because a substantial number of future responders would be lost if all patients with HBsAg levels exceeding 20,000 IU/mL would discontinue therapy at week 24. Therefore, additional studies on $\mathrm{HBeAg}$ and HBsAg quantification are needed to validate these assays before they can be of true predictive value during PEG-IFN treatment for $\mathrm{HBeAg}$-positive CHB.

\section{Interferon-Based Therapy for HBeAg-Negative Chronic Hepatitis B}

\section{Response Rates}

In older studies, patients with HBeAg-negative CHB responded well to conventional IFN. A treatment course of 3 to 6 months resulted in an end-of-treatment response in many patients [32]. However, response was not durable in a large proportion of these patients, and relapse occurred in about half of initial responders after treatment discontinuation [32].

PEG-IFN treatment has been less extensively studied in HBeAg-negative patients. In one large trial, PEG-IFN $\alpha-2 \mathrm{a}$ monotherapy for 48 weeks resulted in a combined response (HBV DNA $<20,000$ copies/mL and normalization of ALT) in $36 \%$ of patients at 24 weeks after treatment discontinuation [33]. A serum HBV DNA level less than
400 copies $/ \mathrm{mL}$ was observed in $19 \%$ of patients. Six months after treatment discontinuation, $4 \%$ of $\mathrm{HBeAg}$ negative patients had cleared HBsAg. In parallel with HBeAg-positive disease, addition of LAM to PEG-IFN improved end-of-treatment response rates, but this difference was not sustained posttreatment [33].

Results of long-term follow-up studies have shown that the off-treatment sustainability of response to PEG-IFN is lower in HBeAg-negative compared with HBeAg-positive disease. At 3 years after discontinuation of PEG-IFN $\alpha-2 \mathrm{a}$ therapy, a sustained virologic response (HBV DNA $<10,000$ copies/mL at 6 months after treatment discontinuation) proved to be durable in $43 \%$ of the initial responders. The rate of HBsAg loss increased to $9 \%[34 \bullet \bullet]$.

\section{Predictors of Response at Baseline}

It is a major challenge to identify HBeAg-negative patients who are likely to benefit from PEG-IFN therapy before treatment is initiated or as early as possible during the treatment course. Unfortunately, baseline predictors of response to PEG-IFN are poorly defined in comparison with $\mathrm{HBeAg}$-positive disease. A post-hoc analysis of the study investigating the efficacy of PEG-IFN $\alpha-2 \mathrm{a}$ for HBeAg-negative $\mathrm{CHB}$ reported that lower baseline serum HBV DNA levels, higher ALT levels, younger age, female gender, and HBV genotype B and C (compared to D) were significantly associated with higher sustained response rates [35]. However, the clinical usefulness of these predictors is limited when considering individual patients for PEG-IFN therapy.

\section{On-Treatment Predictors of Response}

Because baseline predictors of response to PEG-IFN are poorly defined in HBeAg-negative patients, recent studies have focused on the identification of markers allowing ontreatment prediction of response. Previous reports indicated that prediction of response to PEG-IFN by means of serum HBV DNA levels is difficult [36]. Besides HBV DNA, HBsAg is the only viral marker that remains detectable in the serum of $\mathrm{CHB}$ patients who become HBeAg negative. A retrospective study in $\mathrm{HBeAg}$-negative patients treated with PEG-IFN $\alpha$-2a showed that an end-of-treatment HBsAg level below $10 \mathrm{IU} / \mathrm{mL}$ and an on-treatment decline greater than $1 \log _{10} \mathrm{IU} / \mathrm{mL}$ were significantly associated with sustained HBsAg clearance 3 years after treatment [37•]. These results suggest HBsAg decline during PEG-IFN therapy may allow discrimination between future responders and nonresponders. In a cohort of 48 patients treated with PEG-IFN $\alpha-2 \mathrm{a}$ for 48 weeks, high predictive values for on-treatment $\mathrm{HBsAg}$ declines at weeks 12 and 24 on sustained virologic response 
(HBV DNA below 70 copies $/ \mathrm{mL}$ ) were reported [38]. Patients with more than $0.5 \log _{10} \mathrm{IU} / \mathrm{mL} \mathrm{HBsAg}$ decline at week 12 had an $89 \%$ probability of response, whereas those who did not achieve this amount of HBsAg decline had a $90 \%$ chance of nonresponse. In contrast, we recently reported that ontreatment HBsAg decline at week 12 alone was of limited value in predicting sustained response (HBV DNA $<10,000$ copies $/ \mathrm{mL}[\approx 2,000 \mathrm{IU} / \mathrm{mL}]$ and normal ALT at 24 weeks after treatment discontinuation) in 107 patients treated with PEG-IFN $\alpha-2 \mathrm{a}$ (with or without ribavirin) for 48 weeks in a randomized controlled trial. However, through a combination of HBsAg and HBV DNA declines at week 12, we were able to establish a solid stopping rule. None of the 20 patients ( $20 \%$ of the study population) in whom a decrease in serum HBsAg level was absent and HBV DNA declined less than $2 \log _{10}$ copies/mL achieved a sustained response (negative predictive value $100 \%$ ) [39].

\section{Potential Treatment Strategies}

\section{Combination Therapy}

Combination therapy theoretically offers advantages compared to monotherapy, including a combination of immunomodulatory and antiviral effects, synergistic antiviral effects, and a higher barrier toward resistance. Several studies have assessed whether the addition of a first generation NA to PEG-IFN therapy improves treatment outcomes. Irrespective of $\mathrm{HBeAg}$ status, the addition of LAM to PEG-IFN resulted in a higher degree of ontreatment viral suppression, but similar sustained off-treatment response compared to PEG-IFN alone [18, 19, 33]. PEG-IFN $\alpha-2 b$ and adefovir (ADV) combination therapy resulted in rates of $\mathrm{HBeAg}$ loss and seroconversion similar to those found in individuals treated with PEG-IFN alone or in combination with LAM [30]. Furthermore, no differences in sustained virologic and biochemical response rates were observed between HBeAg-negative patients treated with PEG-IFN $\alpha$-2a monotherapy and PEG-IFN and ADV combination therapy [40]. We recently reported that combining PEG-IFN $\alpha-2 a$ with the immunomodulatory agent ribavirin (RBV) did not lead to higher response rates for the treatment of HBeAg-negative patients, compared with PEG-IFN monotherapy [41].

Lowering the viral load before initiating PEG-IFN therapy may increase response rates, given the association of lower baseline HBV DNA levels with a higher probability of response; however, results have been conflicting $[42,43]$.

\section{Duration of Treatment}

Conventional IFN was typically given for 12 to 24 weeks in $\mathrm{HBeAg}$-positive patients. One could therefore question whether PEG-IFN could be given for less than 48 weeks, as is currently recommended by the manufacturer. Response rates to 24 weeks of PEG-IFN $\alpha$-2a in HBeAg-positive CHB appear to be in the range of those in other studies with longer treatment duration, but comparison of these results must be undertaken with caution because patient populations and PEG-IFN doses differed between studies [3, 18, 19].

Studies using conventional IFN suggested the risk of relapse after treatment discontinuation may be diminished with extended treatment in $\mathrm{HBeAg}$-negative patients [44]. A recent study confirmed that 2 years of PEG-IFN $\alpha-2 \mathrm{a}$ therapy significantly increased the rate of sustained response (HBV DNA $\leq 2,000 \mathrm{IU} / \mathrm{mL}$ at 1 year after treatment discontinuation) in genotype $\mathrm{D}$ infected $\mathrm{HBeAg-negative}$ patients compared with the currently recommended duration of 1 year $(31 \%$ vs $10 \%, P=0.01)$ [45].

\section{Side-Effects of Interferon-Based Therapy}

In contrast to the well-tolerated NA, IFN-based therapy is often complicated by the occurrence of side effects. Flu-like syndrome, headache, myalgia, fatigue, and local reaction at the injection site are reported most frequently, but do not require discontinuation of therapy in most cases $[18,19,33$, 46]. Other clinically relevant side effects, including anorexia, thyroid dysfunction, and hepatitis flares, occur less frequently. Furthermore, neuropsychiatric symptoms (depression, agitation, sleeping disturbances) are a major concern. PEG-IFN has myelosuppressive effects, but clinically relevant neutropenia or thrombopenia are infrequently observed, except in patients with cirrhosis who have decreased cell counts before starting therapy [46].

Although PEG-IFN $\alpha-2 b$ in $\mathrm{HBeAg}$-positive patients with advanced fibrosis but compensated liver disease proved to be well tolerated and effective [47], decompensated liver disease remains an absolute contraindication for PEG-IFN treatment because of the risk of IFN-induced hepatitis flares resulting in hepatic decompensation [48]. Other important contraindications include severe psychiatric disorders (depression and suicidal ideation), severe cardiac disease, and autoimmune hepatitis (or other autoimmune disorders).

\section{Discussion}

Current treatment options for CHB consist of five NA and PEG-IFN [1]. Both treatment modalities are effective and can improve long-term outcome. To select the optimal first-line drug, the advantages and limitations of each agent as well as patient-specific characteristics should be taken into account. NA therapy offers oral administration and 
newly registered NA are able to maintain suppression of viral replication in most patients for prolonged periods. However, it is uncertain whether oral antiviral therapy can be discontinued, thus necessitating indefinite therapy in many patients $[49,50]$. Although NA are well tolerated, extended therapy poses a risk for antiviral resistance and long-term safety is currently unknown [2]. PEG-IFN therapy offers the advantage of higher sustained response rates compared to NA because of its immunomodulatory effects [20••, 34••]. However, PEG-IFN should only be considered for patients who are likely to respond to therapy because of the costs and side-effects associated with this agent. For HBeAg-positive $\mathrm{CHB}$, a prediction model is available that provides good discrimination between responders and nonresponders using readily available baseline parameters (www.liver-gi.nl/peg-ifn) [24••]. Furthermore, on-treatment monitoring of HBV DNA, $\mathrm{HBeAg}$, and HBsAg levels may further tailor therapy for individual patients $[26,28 \cdot, 31]$. Baseline predictors of response are poorly defined in $\mathrm{HBeAg-negative} \mathrm{disease,} \mathrm{but}$ recent results on HBsAg quantification during PEG-IFN therapy are promising [37•, 38, 39].

Combining immunomodulators with an antiviral agent theoretically offers advantages, but the addition of LAM, ADV, and RBV to PEG-IFN therapy did not result in higher sustained response rates $[18,19,33,40,41]$. Combination of PEG-IFN with more potent antiviral agents (entecavir [ETV], tenofovir [TDF]), lowering HBV DNA by NA therapy before commencing PEG-IFN therapy, or prolonging PEG-IFN therapy may improve treatment outcomes [42, 44].

\section{Conclusions}

IFN therapy has been used for to treat CHB for many years. The availability of new, well-tolerated NA has expanded treatment options, but sustained off-treatment viral suppression is yet achieved only in a minority of patients, necessitating indefinite treatment in most instances. Although resistance rates appear to be low for ETV and TDF, long-term resistance and safety data are lacking. The antiviral potency of PEG-IFN is lower compared to NA and the occurrence of side effects is an important concern, but response is more durable in most patients because of its immunomodulatory effects. PEG-IFN therapy therefore should be considered for patients without contraindications and with a high likelihood of response.

Disclosure Dr. Janssen has served as a consultant for and received research grants from Gilead, Roche, Schering-Plough, Bristol-Myers Squibb, and Novartis. No other potential conflict of interest relevant to this article was reported.
Open Access This article is distributed under the terms of the Creative Commons Attribution Noncommercial License which permits any noncommercial use, distribution, and reproduction in any medium, provided the original author(s) and source are credited.

\section{References}

Papers of particular interest, published recently, have been highlighted as:

- Of importance,

•- Of major importance

1. Liaw YF, Chu CM: Hepatitis B virus infection. Lancet 2009, 373:582-92.

2. Zoulim F, Locarnini S: Hepatitis B virus resistance to nucleos $(\mathrm{t})$ ide analogues. Gastroenterology 2009, 137:1593-1608.

3. Cooksley WG, Piratvisuth T, Lee SD, et al.: Peginterferon alpha$2 \mathrm{a}(40 \mathrm{kDa})$ : an advance in the treatment of hepatitis B e antigenpositive chronic hepatitis B. J Viral Hepat 2003, 10:298-305.

4. European Association for the Study of the Liver: EASL Clinical Practice Guidelines: management of chronic hepatitis B. J Hepatol 2009, 50:227-242.

5. Lok AS, McMahon BJ: Chronic hepatitis B: update 2009. Hepatology 2009, 50:661-662.

6. Hadziyannis SJ, Vassilopoulos D: Hepatitis B e antigen-negative chronic hepatitis B. Hepatology 2001, 34:617-624.

7. Locarnini S: Molecular virology of hepatitis B virus. Semin Liver Dis 2004, 24 Suppl 1:3-10.

8. Feld JJ, Wong DK, Heathcote EJ: Endpoints of therapy in chronic hepatitis B. Hepatology 2009, 49:S96-S102.

9. Fattovich G, Olivari N, Pasino M, et al.: Long-term outcome of chronic hepatitis B in Caucasian patients: mortality after 25 years. Gut 2008, 57:84-90.

10. Niederau $\mathrm{C}$, Heintges $\mathrm{T}$, Lange $\mathrm{S}$, et al.: Long-term follow-up of HBeAg-positive patients treated with interferon alfa for chronic hepatitis B. $N$ Engl J Med 1996, 334:1422-1427.

11. van Zonneveld $\mathrm{M}$, Honkoop $\mathrm{P}$, Hansen $\mathrm{BE}$, et al.: Long-term follow-up of alpha-interferon treatment of patients with chronic hepatitis B. Hepatology 2004, 39:804-810.

12. Chen CJ, Yang HI, Su J, et al.: Risk of hepatocellular carcinoma across a biological gradient of serum hepatitis B virus DNA level. JAMA 2006, 295:65-73.

13. Iloeje UH, Yang HI, Su J, et al.: Predicting cirrhosis risk based on the level of circulating hepatitis B viral load. Gastroenterology 2006, 130:678-686.

14. Fattovich G, Bortolotti F, Donato F: Natural history of chronic hepatitis B: special emphasis on disease progression and prognostic factors. $J$ Hepatol 2008, 48:335-352.

15. Peters M: Actions of cytokines on the immune response and viral interactions: an overview. Hepatology 1996, 23:909-916.

16. Craxi A, Cooksley WG: Pegylated interferons for chronic hepatitis B. Antiviral Res 2003, 60:87-89.

17. Wong DK, Cheung AM, O'Rourke K, et al.: Effect of alphainterferon treatment in patients with hepatitis $\mathrm{B}$ e antigen-positive chronic hepatitis B. A meta-analysis. Ann Intern Med 1993, 119:312-323.

18. Janssen HL, van Zonneveld M, Senturk H, et al.: Pegylated interferon alfa- $2 b$ alone or in combination with lamivudine for HBeAg-positive chronic hepatitis B: a randomised trial. Lancet 2005, 365:123-129.

19. Lau GK, Piratvisuth T, Luo KX, et al.: Peginterferon Alfa-2a, lamivudine, and the combination for $\mathrm{HBeAg}$-positive chronic hepatitis B. N Engl J Med 2005, 352:2682-2695. 
20. •• Buster EH, Flink HJ, Cakaloglu Y, et al.: Sustained HBeAg and HBsAg loss after long-term follow-up of $\mathrm{HBeAg}$-positive patients treated with peginterferon alpha-2b. Gastroenterology 2008, 135:459-467. This report describes the durability of HBeAg loss induced by PEG-IFN therapy for HBeAg-positive CHB.

21. Fung SK, Lok AS: Hepatitis B virus genotypes: do they play a role in the outcome of HBV infection? Hepatology 2004, 40:790-792.

22. Erhardt A, Blondin D, Hauck K, et al.: Response to interferon alfa is hepatitis B virus genotype dependent: genotype A is more sensitive to interferon than genotype D. Gut 2005, 54:1009-1013.

23. Wai CT, Chu CJ, Hussain M, et al.: HBV genotype B is associated with better response to interferon therapy in $\mathrm{HBeAg}(+)$ chronic hepatitis than genotype C. Hepatology 2002, 36:1425-1430.

24. • Buster EH, Hansen BE, Lau GK, et al.: Factors that predict response of patients with hepatitis $\mathrm{B}$ e antigen-positive chronic hepatitis B to peginterferon-alfa. Gastroenterology 2009, 137:2002-2009. This important study provides a decision rule for prediction of response to PEG-IFN therapy at baseline based on the two largest PEG-IFN trials for HBeAg-positive CHB.

25. ter Borg MJ, van Zonneveld M, Zeuzem S, et al.: Patterns of viral decline during PEG-interferon alpha-2b therapy in $\mathrm{HBeAg}-$ positive chronic hepatitis $\mathrm{B}$ : relation to treatment response. Hepatology 2006, 44:721-727.

26. Hansen BE, Buster EH, Steyerberg EW, et al.: Prediction of the response to peg-interferon-alfa in patients with $\mathrm{HBeAg}$ positive chronic hepatitis B using decline of HBV DNA during treatment. J Med Virol 2010, 82:1135-1142.

27. Nguyen T, Desmond P, Locarnini S: The role of quantitative hepatitis B serology in the natural history and management of chronic hepatitis B. Hepatol Int 2009, 3:S5-S15.

28. • Fried MW, Piratvisuth T, Lau GK, et al.: HBeAg and hepatitis B virus DNA as outcome predictors during therapy with peginterferon alfa-2a for $\mathrm{HBeAg}$-positive chronic hepatitis B. Hepatology 2008, 47:428-434. The potential of quantitative HBeAg for predicting response to PEG-IFN therapy in HBeAg-positive patients is investigated in this study.

29. Werle-Lapostolle B, Bowden S, Locarnini S, et al.: Persistence of cccDNA during the natural history of chronic hepatitis B and decline during adefovir dipivoxil therapy. Gastroenterology 2004, 126:1750-1758.

30. Wursthorn K, Lutgehetmann M, Dandri M, et al.: Peginterferon alpha-2b plus adefovir induce strong cccDNA decline and HBsAg reduction in patients with chronic hepatitis B. Hepatology 2006, 44:675-684.

31. Lau GKK, Marcellin P, Brunetto $\mathrm{M}$, et al.: On-treatment monitoring of HBsAg levels to predict response to peginterferon alfa-2a in patients with HBeAg-positive chronic hepatitis B. $J$ Hepatol 2009, 50:S333.

32. Hadziyannis SJ: Treatment paradigms on hepatitis B e antigennegative chronic hepatitis B patients. Expert Opin Investig Drugs 2007, 16:777-786.

33. Marcellin P, Lau GK, Bonino F, et al.: Peginterferon alfa-2a alone, lamivudine alone, and the two in combination in patients with HBeAg-negative chronic hepatitis B. N Engl J Med 2004, 351:1206-1217.

34. •• Marcellin P, Bonino F, Lau GK, et al.: Sustained response of hepatitis $B$ e antigen-negative patients 3 years after treatment with peginterferon alpha-2a. Gastroenterology 2009, 136:2169-2179. This important study describes the durability of response to PEGIFN therapy in HBeAg-negative patients.
35. Bonino F, Marcellin P, Lau GK, et al.: Predicting response to peginterferon alpha-2a, lamivudine and the two combined for HBeAg-negative chronic hepatitis B. Gut 2007, 56:699-705.

36. Farci P, Marcellin P, Lu ZM, et al.: On-treatment predictors of sustained biochemical and virological response in patients with $\mathrm{HBeAg}$-negative chronic hepatitis $\mathrm{B}(\mathrm{CHB})$ treated with peginterferon alpha-2a (40 kDa) (Pegasys(R)). J Hepatol 2005, 42:S175.

37. - Brunetto MR, Moriconi F, Bonino F, et al.: Hepatitis B virus surface antigen levels: a guide to sustained response to peginterferon alfa-2a in HBeAg-negative chronic hepatitis B. Hepatology 2009, 49:1141-1150. This study investigates the role of quantitative HBsAg in prediction of sustained response to PEG-IFN therapy.

38. Moucari R, Mackiewicz V, Lada O, et al.: Early serum HBsAg drop: a strong predictor of sustained virological response to pegylated interferon alfa-2a in HBeAg-negative patients. Hepatology 2009, 49:1151-1157.

39. Rijckborst V, Hansen BE, Cakaloglu Y, et al.: Early prediction of sustained response to peginterferon alfa-2a in HBeAg-negative patients: The role of on-treatment HBsAg and HBV DNA levels. $J$ Hepatol 2010, 52:S4-S5.

40. Piccolo P, Lenci I, Demelia L, et al.: A randomized controlled trial of pegylated interferon-alpha2a plus adefovir dipivoxil for hepatitis B e antigen-negative chronic hepatitis B. Antivir Ther 2009, 14:1165-1174.

41. Rijckborst V, Ter Borg MJ, Cakaloglu Y, et al.: A randomized trial of peginterferon alpha-2a with or without ribavirin for HBeAg-negative chronic hepatitis B. Am J Gastroenterol 2010, 105:1762-1769.

42. Sarin SK, Sood A, Kumar M, et al.: Effect of lowering HBV DNA levels by initial antiviral therapy before adding immunomodulator on treatment of chronic hepatitis B. Am J Gastroenterol 2007, 102:96-104.

43. Chan HL, Wong VW, Chim AM, et al.: Virological response to different combination regimes of peginterferon alpha- $2 b$ and lamivudine in hepatitis B e antigen positive chronic hepatitis B. Antivir Ther 2007, 12:815-823.

44. Lampertico P, Del Ninno E, Vigano $\mathrm{M}$, et al.: Long-term suppression of hepatitis B e antigen-negative chronic hepatitis B by 24-month interferon therapy. Hepatology 2003, 37:756-763.

45. Lampertico P, Vigano M, Di Costanzo G, et al.: Extended (2 years) treatment with peginterferon alfa-2a [40 kD] improves sustained response rates in genotype D patients with $\mathrm{HBeAg}$ negative chronic hepatitis B. J Hepatol 2010, 52:S45.

46. van Zonneveld M, Flink HJ, Verhey E, et al.: The safety of pegylated interferon alpha- $2 \mathrm{~b}$ in the treatment of chronic hepatitis B: predictive factors for dose reduction and treatment discontinuation. Aliment Pharmacol Ther 2005, 21:1163-1171.

47. Buster EH, Hansen BE, Buti M, et al.: Peginterferon alpha-2b is safe and effective in HBeAg-positive chronic hepatitis B patients with advanced fibrosis. Hepatology 2007, 46:388-394.

48. Janssen HL, Brouwer JT, Nevens F, et al.: Fatal hepatic decompensation associated with interferon alfa. European concerted action on viral hepatitis (Eurohep). BMJ 1993, 306:107-108.

49. Shouval D, Lai CL, Chang TT, et al.: Relapse of hepatitis B in HBeAg-negative chronic hepatitis B patients who discontinued successful entecavir treatment: the case for continuous antiviral therapy. J Hepatol 2009, 50:289-295.

50. Dienstag JL, Cianciara J, Karayalcin S, et al.: Durability of serologic response after lamivudine treatment of chronic hepatitis B. Hepatology 2003, 37:748-755. 